\title{
Advances in the Synthesis of Fluorinated Scaffolds by Transition Metal-Catalyzed C-H Bond Activation
}

\author{
Sara Mazeha, Maria Ivana Lapuha, and Tatiana Besset ${ }^{\star}$
}

\begin{abstract}
Thanks to the unique features of the fluorine atom and the fluorinated groups, fluorine-containing molecules are essential. Therefore, the search for new fluorinated groups as well as straightforward and original methodologies for their installation is of prime importance. Especially, the combination of organofluorine chemistry with transition metal-catalyzed $\mathrm{C}-\mathrm{H}$ bond functionalization reactions offered straightforward tools to access original fluorinated scaffolds. In this context, over the last years, our group focused on the development of original methodologies to synthesize fluorine-containing molecules with a special attention to emergent fluorinated groups. The present account highlights our recent contributions to the synthesis of highly value-added fluorine-containing compounds by transition metal-catalyzed $\mathrm{C}-\mathrm{H}$ bond activation.
\end{abstract}

Keywords: C-H bond functionalization · Emergent fluorinated groups · Organofluorine chemistry · Synthetic methods · Transition metal

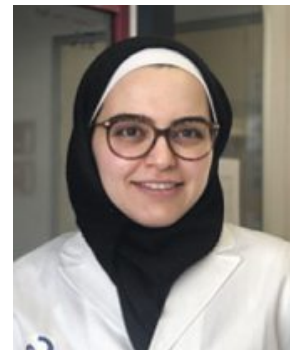

Sara Mazeh studied chemistry at Claude Bernard University, Lyon acquiring her master's degree in 2016. She then completed her doctoral degree in organic chemistry at Grenoble Alpes University in 2019. Her $\mathrm{PhD}$ work focused on the total synthesis of an alkaloid under the supervision of Dr Philippe Delair. Sara has recently joined the COBRA laboratory as a postdoctoral fellow in the 'Fluorinated Biomolecules Synthesis' group (COBRA Laboratory, UMR 6014, Rouen INSA and University, CNRS, Rouen, France) under the supervision of Dr. Tatiana Besset. Her research project focuses on transition metal catalyzed $\mathrm{C}-\mathrm{H}$ bond activation.

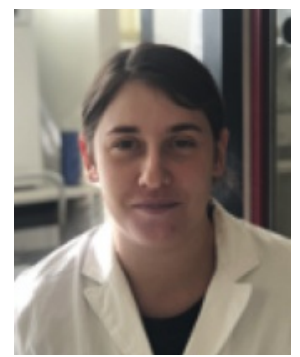

Maria Ivana Lapuh was born in Argentina and got her Chemistry degree and $\mathrm{PhD}$ at the University of Buenos Aires (UMYMFOR CONICET, Organic Chemistry Department, School of Natural Sciences). Her PhD was based on the application of difluoromethylation and $\mathrm{Rh}$ (II)-catalyzed $\mathrm{C}-\mathrm{H}$ amination reactions to the synthesis of molecules with potential antimicrobial activity. During her thesis, she had the opportunity to boost her experience by doing two internships at the Institut de Chimie des Substances Naturelles (ICSN, Gif-sur-Yvette, France) under the supervision of Dr. Philippe Dauban. Currently, she is a post-doctoral fellow in the 'Fluorinated Biomolecules Synthesis' group (COBRA Laboratory, UMR 6014, Rouen INSA and University, CNRS, Rouen, France) under the supervision of Dr. Tatiana Besset.

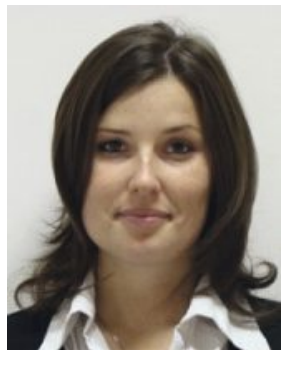

Tatiana Besset obtained her $\mathrm{PhD}$ in chemistry (2009) at Grenoble University with Dr. Andrew Greene. She then moved to the Westfälische Wilhelms Universität Münster (Germany) as a postdoctoral fellow in the group of Prof. Frank Glorius ( $\mathrm{Rh} \mathrm{C}-\mathrm{H}$ bond activation). In 2011, she joined the group of Prof. Joost N. H. Reek at the University of Amsterdam (the Netherlands), as a postdoctoral fellow in collaboration with the Eastman company where she was working on supramolecular encapsulated rhodium catalysts for branched selective hydroformylation of alkenes. Since 2012, she is a CNRS Associate Researcher in the 'Fluorinated Biomolecules Synthesis' group at the laboratory COBRA (UMR 6014) in Rouen, France. In 2017, she was awarded an ERC Starting Grant. In 2018, she defended her habilitation, received the CNRS Bronze medal and the ' $J .-P$. Sauvage' prize (SCF). Her research involves the design of new transformations involving transition metal catalysis $(\mathrm{C}-\mathrm{H}$ bond activation) and the development of new strategies in organofluorine chemistry.

\section{Introduction}

Organofluorine chemistry is a key research field, which has experienced a tremendous interest from the scientific community in the past decades. ${ }^{[1]}$ Nowadays, fluorinated scaffolds are widely found in pharmaceuticals, agrochemicals and materials. ${ }^{[2]}$ Indeed, the presence of a fluorine atom or a fluorinated group in a given molecule can modulate its physico-chemical and biological properties and can have an impact on the conformational changes, the metabolic stability and the physicochemical properties $\left(\mathrm{p} K_{\mathrm{a}}\right.$ and lipophilicity), for instance.[3] In addition, transition metal-catalyzed $\mathrm{C}-\mathrm{H}$ bond functionalization has reshaped the field of organic chemistry providing modern, efficient and more sustainable tools for the direct functionalization of molecules. ${ }^{[4]}$ Since new retro-disconnections are possible, a paradigm shift is observed in the way chemists conceive the synthesis of compounds, offering a formidable access to high molecular complexity. ${ }^{[5]}$ Therefore, merging organofluorine chemistry with transition metal-catalyzed $\mathrm{C}-\mathrm{H}$ bond functionalization turned out to be a highly ap- 
pealing strategy. ${ }^{[6]}$ In recent years, our group has been focused on the development of new methodologies based on this approach to access original and relevant fluorinated scaffolds. In this account, our latest contributions will be summarized.

\section{An Approach to Trifluoromethylated Alkenes}

The trifluoromethyl group is a key moiety in organofluorine chemistry. Consequently, many efforts have been done for its incorporation into molecular scaffolds. ${ }^{[7]}$ Particularly, the $\alpha$-(trifluoromethyl)vinyl residue has received a lot of attention ${ }^{[1 \mathrm{a}}$, b,d,e,6a,e,7b,d,h,8,9] as it might act as $\alpha$-amide bond isostere ${ }^{[10]}$ and was found in several compounds of interest.[11] Therefore, our group focused on the design of two complementary strategies based on transition metal-catalyzed $\mathrm{C}-\mathrm{H}$ bond activation for the synthesis of compounds containing a $\alpha$-(trifluoromethyl)vinyl moiety.

\subsection{Cu-mediated Trifluoromethylation of Acrylamides}

In this context, much effort has been devoted towards the development of new strategies for the construction of a $\mathrm{C}\left(\mathrm{sp}^{2}\right)-\mathrm{CF}_{3}$ bond from a C-H bond by transition metal catalysis. ${ }^{[12]}$ Such approaches generally led to a mixture of $E / Z$ isomers or to the $E$-isomer selectively. ${ }^{[9 s, 12 a, 13]}$ In contrast, strategies for the trifluoromethylation of olefins with a total control of the selectivity towards the $Z$-isomers are much less reported. ${ }^{9 \mathrm{~m}, 14]}$ Therefore, our group depicted a methodology for the trifluoromethylation of acrylamides to access the difficult-to-synthesize $Z$-isomers. ${ }^{[15]}$ Indeed, a Cu-mediated $\beta$-trifluoromethylation of $N, N$-diethylacrylamides (1) was developed using the Umemoto reagent (I) in the presence of trifluoroacetic acid (TFA) and $N$-methylformamide under air (Scheme $1)$. With this approach, an array of $\alpha$-aryl substituted acrylamides was trifluoromethylated providing the corresponding products $\mathbf{2}$ as single Z-diastereoisomers. Note that only the mono-trifluoromethylation reaction occurred. $\alpha$-Aryl-substituted acrylamides bearing a halogen (1b) as well as electron-donating groups (1c and 1d) were smoothly functionalized. Interestingly, an amide bearing an alkyl chain at the $\alpha$-position (1e) was trifluoromethylated in $19 \%$ yield, due to a competitive isomerization of the double bond affording the trifluoromethylated allylic compound as a side-product. Pleasingly, acrylamides with different substitution patterns (1f and $\mathbf{1 g}$ ) were also functionalized, albeit in somehow lower yields, leading to high-value-added tri- and tetrasubstituted olefins.

\subsection{Pd-catalyzed Synthesis of $\alpha$-(Trifluoromethyl)sty- renes}

Later in 2016, a complementary route was designed to build up $\alpha$-(trifluoromethyl)styryl derivatives using 2-bromo-3,3,3-trifluoropropene (BTP, II $)^{[16]}$ as the source of the $\alpha$-(trifluoromethyl) vinyl moiety. Indeed, the BTP was selected as it is an inexpensive, readily available and non-ozone depleting reagent, which was al-

Cul (1.1 equiv)
$\begin{aligned} & \text { 2a, } \mathrm{R}=\mathrm{H}, 67 \% \\ & \mathbf{2 b}, \mathrm{R}=4-\mathrm{Cl}_{5}, 54 \% \\ & \mathbf{2 c}, \mathrm{R}=4-\mathrm{OM}, 69 \% \\ & \mathbf{2 d}, \mathrm{R}=2-\mathrm{Et}_{3}, 34 \%\end{aligned}$

Scheme 1. Regio- and diastereoselective $\mathrm{Cu}(\mathrm{I})$-mediated trifluoromethylation of acrylamides. ready used as a fire suppressant agent, ${ }^{[17]}$ in several cross-coupling reactions ${ }^{[18]}$ and in the synthesis of trifluoromethylated heterocycles. ${ }^{[19]}$ Hence, the first use of the BTP as a coupling partner in a Pd-catalyzed $\mathrm{C}-\mathrm{H}$ bond activation reaction was developed for the synthesis of the $\alpha$-(trifluoromethyl)styryl derivatives. ${ }^{\text {[20] }}$ In the presence of AgOTf, an array of $N$-pivaloylanilines 3 was efficiently functionalized under mild conditions, offering a selective access to the mono-functionalized products $\mathbf{4}$ (up to $78 \%$ yield, Scheme 2). This methodology was compatible with the anilide $\mathbf{3 a}$ as well as with substrates substituted with electron-donating (3b and $\mathbf{3 e}$ ) and electron-withdrawing groups (3c and $\mathbf{3 f}$ ) as well as with a halogen (3d). Note that the substitution pattern of the anilides did not have an impact on the outcome of the transformation and the ortho-substituted anilide (3g) was smoothly functionalized in $72 \%$ yield. This methodology was successfully applied to the functionalization of disubstituted anilines ( $\mathbf{3 h}$ and $\mathbf{3 i}$ ), although the product $4 \mathbf{i}$ was obtained with a lower yield. Pleasingly, it is worth mentioning that the pivaloyl group might be easily cleaved leading to the corresponding aniline.

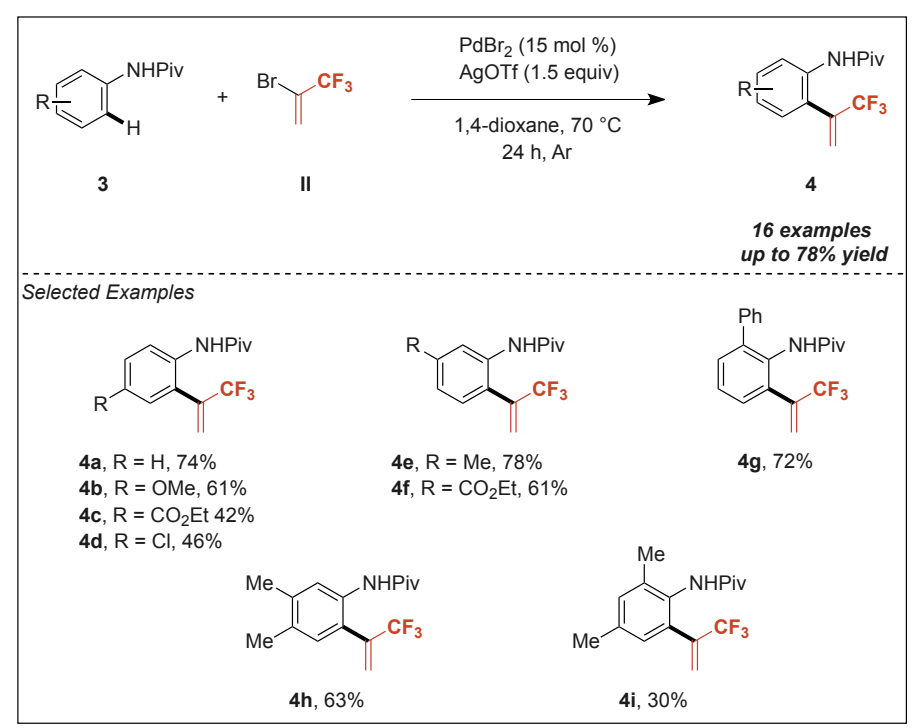

Scheme 2. Synthesis of $\alpha$-(trifluoromethyl)styrenes under palladium catalysis.

\subsection{Pd-catalyzed Synthesis of 3-Trifluoromethyl- substituted 1,3-Butadienes}

Over the years, 1,3-butadienes have received considerable attention owing to their abundance in natural products (e.g. retinoids) ${ }^{[21]}$ and since they were successfully used to access molecular complexity. ${ }^{[22]}$ In contrast, trifluoromethylated 1,3-butadienes are underexplored despite the interest of such building blocks. Therefore, the development of a method to access $Z$-trifluoromethylated 1,3-dienes by a Pd-catalyzed $\mathrm{C}-\mathrm{H}$ bond activation reaction is of paramount importance. ${ }^{[23]}$ The challenge was not only to selectively get the $Z$-isomer as a single product but also to favor the reaction between two similar coupling partners over any possible competitive reactions. In 2017, the Pd-catalyzed $\mathrm{C}-\mathrm{H}$ bond functionalization of $\alpha$-(hetero)aryl substituted acrylamides 5 with BTP in the presence of AgOTf was reported, offering an efficient and stereoselective route to the trifluoromethylated 1,3-dienes 6 (Scheme 3). Acrylamides substituted at the $\alpha$-position with a phenyl group (5a), electronrich arenes (5b and $\mathbf{5 e})$ as well as arenes bearing a halogen $(\mathbf{5 c}, \mathbf{5 d}$ and 5f) were smoothly functionalized (up to $63 \%$ yield). In addition, the methodology was also compatible with the $\alpha$-heteroarylacrylamide $\mathbf{5 g}$. In the case of simple $N, N$-diisopropyl acrylamide $\mathbf{5 h}$ and $\beta$-substituted $\mathbf{5 i}$ and $\mathbf{5 j}$, only the $E$-isomers were selectively obtained probably due to an in situ Pd-catalyzed isomerization of 
the products. ${ }^{[24]}$ The methodology was extended to the synthesis of the pentafluoroethylated dienes (7a-d) using 2-bromo-3,3,4,4,4pentafluorobutene (III) as the coupling partner. In order to get a better understanding of the reaction mechanism involved in this transformation, mechanistic studies along with DFT calculations were conducted and it turned out that there was no H/D scrambling and a KIE of 1.1 was measured. Hence, a plausible redox neutral Pd(II)/ $\mathrm{Pd}(\mathrm{II})$ catalytic pathway was suggested. First, formation of the palladacycle intermediate A would occur followed by a BTP coordination affording the intermediate $\mathbf{B}$. Subsequently, a carbopalladation step would take place leading to the formation of intermediate $\mathbf{C}$. After a Ag-assisted bromide elimination step, ${ }^{[25]}$ the desired product 6 would be released as a single Z-isomer. Note that thanks to DFT calculations, a $\mathrm{Pd}(\mathrm{II}) / \mathrm{Pd}(\mathrm{IV})$ mechanism was ruled out.

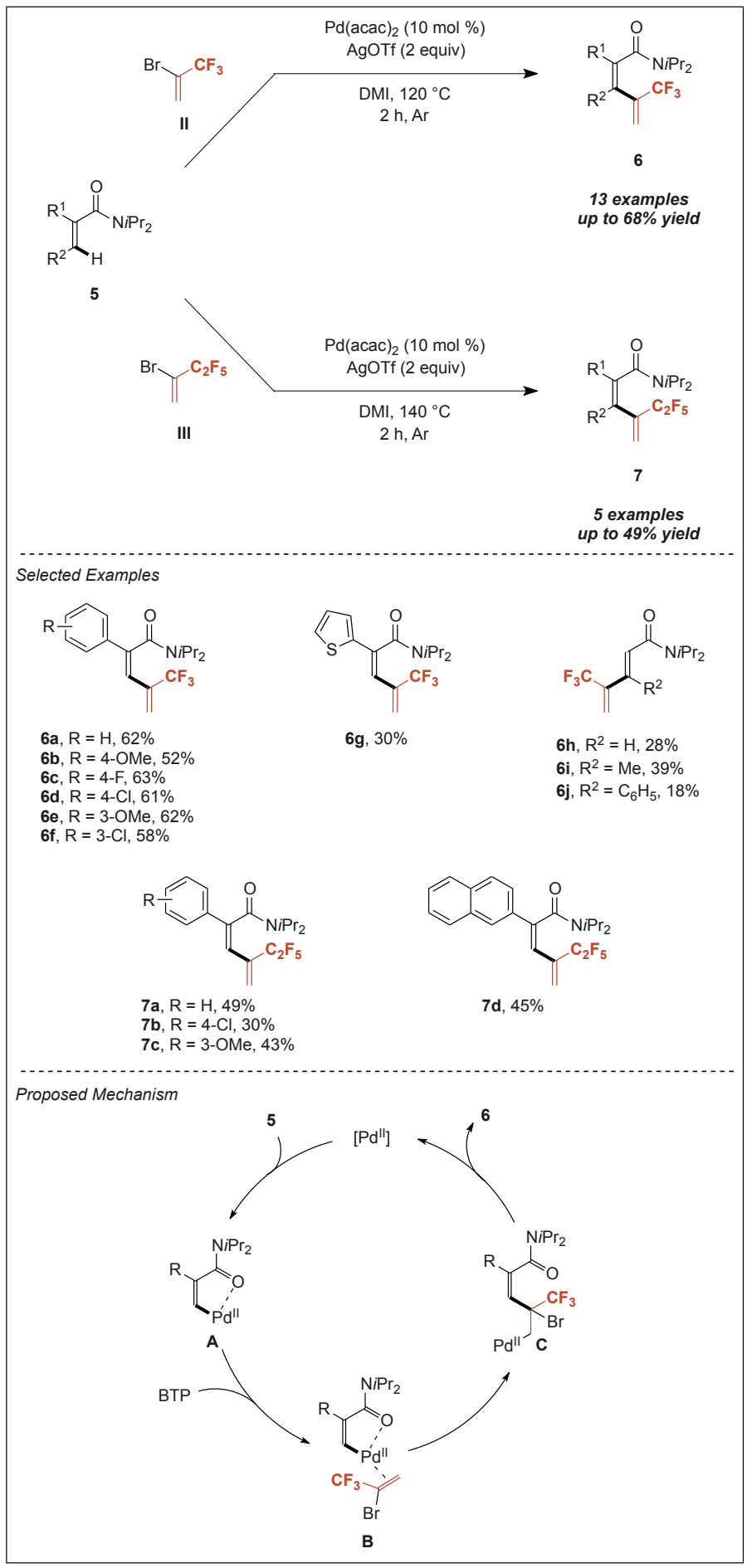

Scheme 3. Pd(II)-catalyzed synthesis of 3-trifluoromethyl-substituted 1,3-butadienes.

\section{Pd-catalyzed Direct Trifluoromethylthiolation of $\mathrm{C}\left(\mathrm{sp}^{2}\right)-\mathrm{H}$ and $\mathrm{C}\left(\mathrm{sp}^{3}\right)-\mathrm{H}$ Bonds}

In recent years, special attention has been paid to the $\mathrm{SCF}_{3}$ group. ${ }^{[26]}$ This emergent fluorinated motif exhibits very interesting properties such as high electron-withdrawing character and lipophilicity (Hansch hydrophobic parameter: $\pi=1.44$ ).[27] Consequently, many transformations were developed to introduce this moiety in different classes of molecules. ${ }^{[26,28-31]}$ Moreover, trifluoromethylthiolated compounds can be found in marketed agrochemical products such as Toltaxuril (coccidiostatic drug) and Fipronil (insecticide), for instance. Nevertheless, despite these advances, the quest for original straightforward methodologies for the preparation of trifluoromethylthiolated compounds is a still challenging research topic.

\subsection{Pd(II)-catalyzed Directed Trifluoromethylthiolation of Unsaturated Compounds}

In the past years, different approaches were developed for the preparation of vinyl trifluoromethylthioethers. One synthetic pathway relied on the use of a prefunctionalized vinylic starting material such as vinyl boronic acids, ${ }^{[28 a, b, h, i, 32]}$ vinyl halides or pseudo halides, ${ }^{[28 r, 33]}$ and cinnamic acids ${ }^{[28 q]}$ through transition metal-promoted reactions. Moreover, trifluoromethylthiolated alkenes could be also obtained from alkynes. ${ }^{[34]}$ In contrast, only few examples dealt with the direct trifluoromethylthiolation of alkenes starting either from terminal olefins ${ }^{[30 \mathrm{~b}, \mathrm{c}]}$ or enamines. ${ }^{[30 \mathrm{a}, \mathrm{d}]}$ In most cases, the $E$-products or $E / Z$ mixture of products were generally obtained. Thus, the selective preparation of $Z$-trifluoromethylthiolated olefins remained elusive. Therefore, this synthetic challenge was tackled with the Pd-catalyzed diastereoselective trifluoromethylthiolation of acrylamides (Scheme 4). ${ }^{[35,36]}$ Indeed, a methodology was developed for the functionalization of different $\alpha$-substituted and $\alpha, \beta$-disubstituted acrylamides 8 derived from the 8 -aminoquinoline. The use of the electrophilic $\mathrm{SCF}_{3}$ source IV (Munavalli reagent) at $80{ }^{\circ} \mathrm{C}$ under an air atmosphere allowed the preparation of the trifluoromethylthiolated compounds 9 in up to $89 \%$ yield with exclusive obtention of $Z$-alkenes. First, an array of $\alpha$-aryl-substituted acrylamides $\mathbf{8 a}-\mathbf{h}$ was used as substrates, demonstrating that the reaction was tolerant to electron-donating $(t \mathrm{Bu}, \mathrm{OMe}, \mathbf{8 b}, \mathbf{8 e}$ and $\mathbf{8 g})$ and electron-withdrawing groups $\left(\mathrm{CF}_{3}, \mathbf{8 f}\right)$. Moreover, the substitution pattern on the aromatic ring did not have a strong influence on the yields (9e $v s 9 \mathbf{g})$. Remarkably, the transformation was compatible with substrates containing a halogen on the aromatic ring $(\mathbf{8 c}$, $\mathbf{8 d}$ and $\mathbf{8 h}$ ), even with the more reactive aryl iodide $\mathbf{8 c}$, allowing possible post-functionalization reactions. Then, acrylamides substituted with naphthyl, 1,3-benzodioxol-5-yl and pyridyl groups at the $\alpha$-position were engaged, furnishing the corresponding trifluoromethylthiolated products $\mathbf{9 i}-\mathbf{k}$ in moderate to high yields. Finally, $\alpha$-methyl and $\alpha, \beta$-dimethyl acrylamides were tested (81 and $\mathbf{8 m}$ ), providing the $Z$-trifluoromethylthiolated product (9l) and the challenging tetrasubstituted alkene $(\mathbf{9 m})$. Note that the use of the amide derived from 5-methoxy-8-aminoquinoline as a directing group (8n) was also possible in this transformation (9n). In order to gain some insight into the reaction mechanism, scrambling experiments were carried out, showing that H/D exchanges occurred during the reaction and a KIE of 2.4 was determined. These experiments denoted that the $\mathrm{C}-\mathrm{H}$ activation step was reversible and probably the rate-determining one. Taking into consideration these observations, the following mechanism was suggested (Scheme 4): coordination of the Pd-catalyst to the bidentate directing group (intermediate $\mathbf{A}$ ) followed by the reversible formation of the palladacycle $\mathbf{B}$. This latter would undergo an oxidative addition with the Munavalli reagent to afford a putative $\mathrm{Pd}(\mathrm{IV})$ intermediate $\mathbf{C}$ and after a reductive elimination and protonation steps, the target compounds $\mathbf{9}$ would be obtained, and the catalyst would be regenerated. 


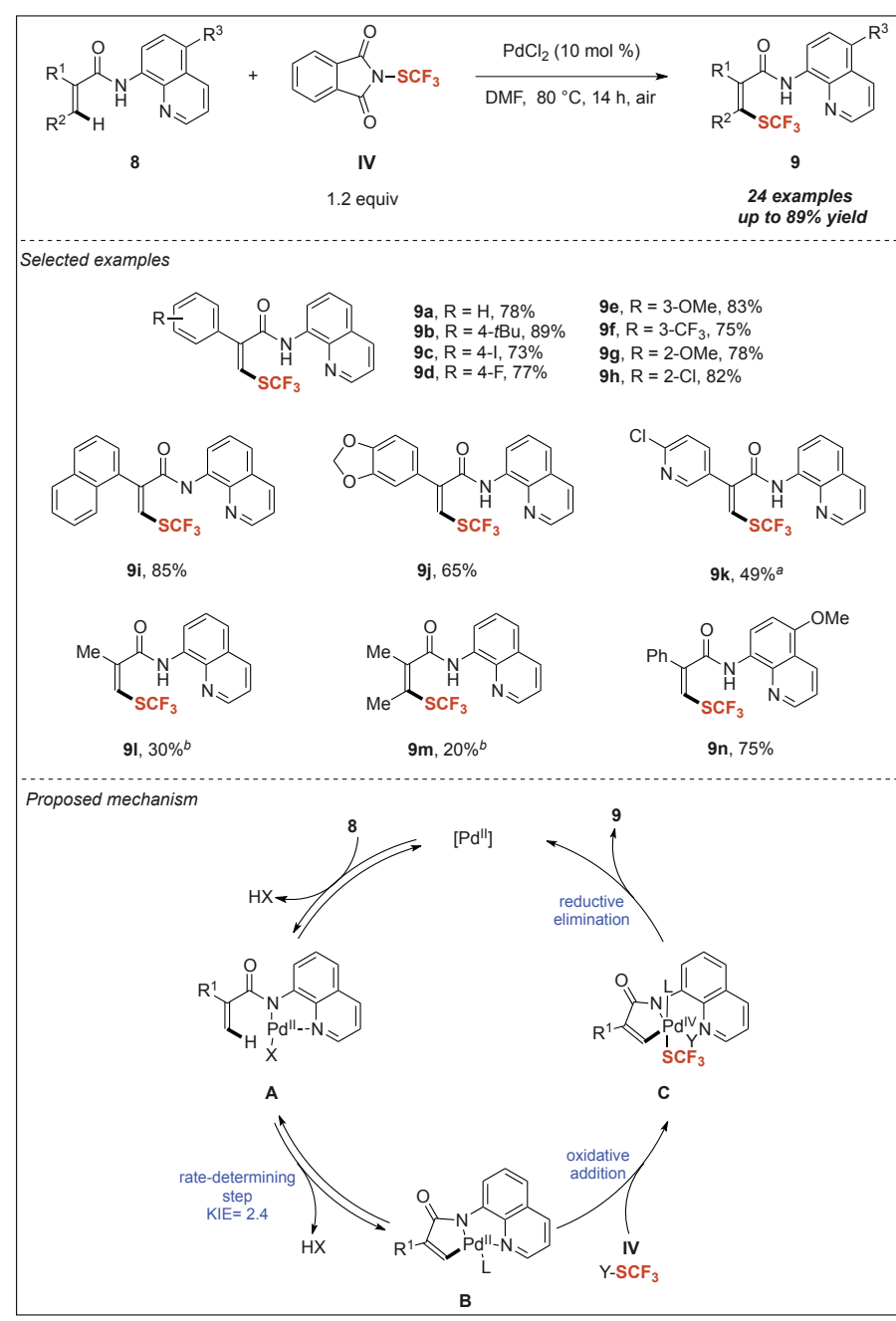

Scheme 4. $\mathrm{Pd}(\mathrm{II})$-catalyzed $\mathrm{C}\left(\mathrm{sp}^{2}\right)-\mathrm{H}$ trifluoromethylthiolation of acrylamide derivatives. a: Using $20 \mathrm{~mol} \%$ of $\mathrm{PdCl}_{2}$ and 2 equiv. of IV (36 h). b: Using $30 \mathrm{~mol} \%$ of $\mathrm{PdCl}_{2}$ and 2 equiv. of IV.

Having demonstrated the value of this method to introduce the $\mathrm{SCF}_{3}$ group into acrylamide derivatives, we aimed at developing a general approach for the functionalization of $\mathrm{C}\left(\mathrm{sp}^{2}\right)-\mathrm{H}$ bonds by transition metal catalysis. Benzamides $\mathbf{1 0}$ derived from 5-methoxy-8-aminoquinoline were used as starting materials and by using slightly modified reaction conditions, the trifluoromethylthiolation proceeded with yields up to $71 \%$ (Scheme 5). ${ }^{[36]}$ Amides having a substituent at their ortho- or meta-position afforded the corresponding mono-trifluoromethylthiolated products 11a-e. When unsubstituted and para-substituted benzamides were used, di-trifluoromethylthiolation occurred at both

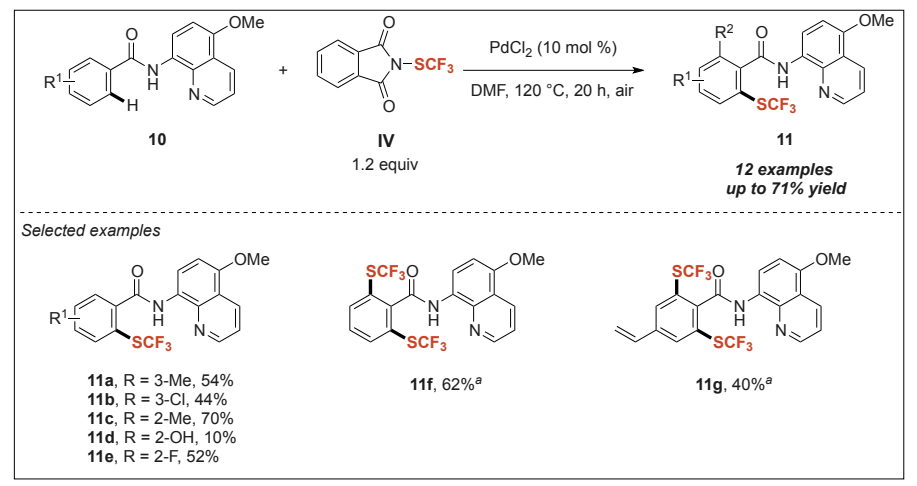

Scheme 5. $\operatorname{Pd}(॥)$-catalyzed trifluoromethylthiolation of benzamides. a: 2.2 equiv of IV were used. ortho-positions when 2.2 equivalents of VI were used (11f and 11g) and no mono-trifluoromethylthiolated product was detected. Pleasingly, the directing group could be smoothly removed under oxidative conditions to afford the corresponding primary amide.

Inspired by the general approach we have developed for the synthesis of trifluoromethylthiolated compounds by Pd-catalyzed $\mathrm{C}-\mathrm{H}$ bond activation, we sought to access biologically relevant compounds and particularly to high-value-added organosulfur compounds. ${ }^{[37]}$ Taking benefit from our expertise in the elaboration of new methodologies to build up $\mathrm{C}-\mathrm{S}$ bonds by transition metalcatalyzed $\mathrm{C}-\mathrm{H}$ bond activation, the synthesis of 4-aryl and 4,5-disubstituted isothiazolone derivatives $\mathbf{1 3}$ was achieved starting from simple acrylamides $\mathbf{1 2}$ in the presence of $N$-thiocyanatophthalimide under palladium catalysis (Scheme 6). ${ }^{[38]}$

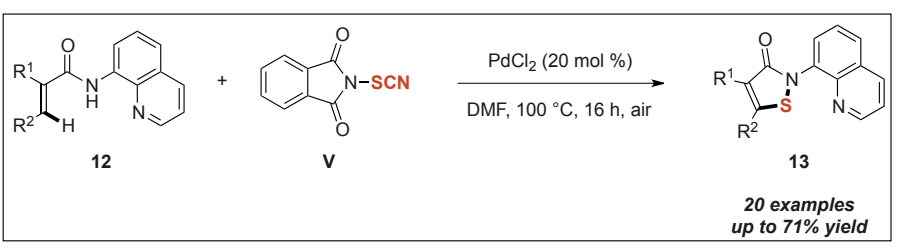

Scheme 6. Application to the synthesis of compounds of interest: an access to isothiazolone derivatives from acrylamides by $\mathrm{Pd}(\mathrm{II})$-catalyzed $\mathrm{C}-\mathrm{H}$ bond activation.

\subsection{Pd(II)-catalyzed Directed Trifluoromethylthiolation of Unactivated C $\left(s p^{3}\right)-H$ Bonds}

The trifluoromethylthiolation of unactivated $\mathrm{C}\left(\mathrm{sp}^{3}\right)-\mathrm{H}$ bonds remains highly challenging and only a handful of examples have been described since 2014. Several reports dealt with the trifluoromethylthiolation of benzylic positions, ${ }^{[31 \mathrm{a}]}$ secondary and tertiary $\mathrm{C}\left(\mathrm{sp}^{3}\right)-\mathrm{H}$ bonds either via $\mathrm{Ag}$-mediated reactions ${ }^{[39-41]}$ or photoredox catalysis. ${ }^{[42]}$ In this context, our group reported for the first time, in 2015, the Pd-catalyzed trifluoromethylthiolation of unactivated primary $\mathrm{C}\left(\mathrm{sp}^{3}\right)$ centers by $\mathrm{C}-\mathrm{H}$ bond activation. ${ }^{[43]}$ Using the combination of an electrophilic $\mathrm{SCF}_{3}$ reagent (Munavalli reagent IV or Billard-Langlois reagent VI) with pivalic acid, the functionalization of primary and secondary $\mathrm{C}\left(\mathrm{sp}^{3}\right)-\mathrm{H}$ bonds on aliphatic amides at the $\beta$-position was achieved (Scheme 7). Note that the use of an amide derived from 8-aminoquinoline as a bidentate directing group was necessary for this transformation. Several amides bearing a $\alpha$-quaternary center $(\mathbf{1 4 a}-\mathbf{i})$ were trifluoromethylthiolated. Remarkably in the case of $\alpha, \alpha$-dimethyl hydrocinnamic acid derivatives $\mathbf{1 4 b} \mathbf{b}-\mathbf{f}$, the selective functionalization of the primary $\mathrm{C}\left(\mathrm{sp}^{3}\right)-\mathrm{H}$ bonds involving a five-membered palladacycle intermediate occurred and no reaction on the more reactive benzylic or aromatic $\mathrm{C}-\mathrm{H}$ bonds was observed. The reaction proved to be tolerant to derivatives substituted with an arene bearing electron-donating (OMe, 14c) and electron-withdrawing groups $\left(\mathrm{CF}_{3}, \mathrm{CN}, \mathbf{1 4 d}\right.$ and 14e) as well as a halogen (14f).

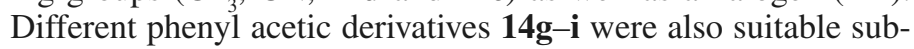
strates, furnishing the corresponding trifluoromethylthiolated products in moderated yields. Furthermore, the methodology was applied to the synthesis of trifluoromethylthiolated analogues of biorelevant molecules such as ibuprofen and naproxen $(\mathbf{1 5} \mathbf{j}$ and 15k), showcasing that the transformation was also possible with amides bearing an $\alpha-\mathrm{C}-\mathrm{H}$ bond. It is worth mentioning that even the trifluoromethylthiolation of secondary $\mathrm{C}\left(\mathrm{sp}^{3}\right)-\mathrm{H}$ bonds was possible with this approach as illustrated with the product 15l, which was obtained in a lower yield. Pleasingly, this transformation was successfully performed in continuous flow, offering access to the trifluoromethylthiolated products in similar yields with a faster process compared to the batch reaction. ${ }^{[44]}$

Regarding the mechanism of the transformation, a similar pathway to the one described in Scheme 4 was suggested involv- 
ing a putative $\operatorname{Pd}(\mathrm{IV})$ intermediate. The presence of the pivalic acid was crucial in this reaction, presumably for the regeneration of the catalyst. ${ }^{[45]}$

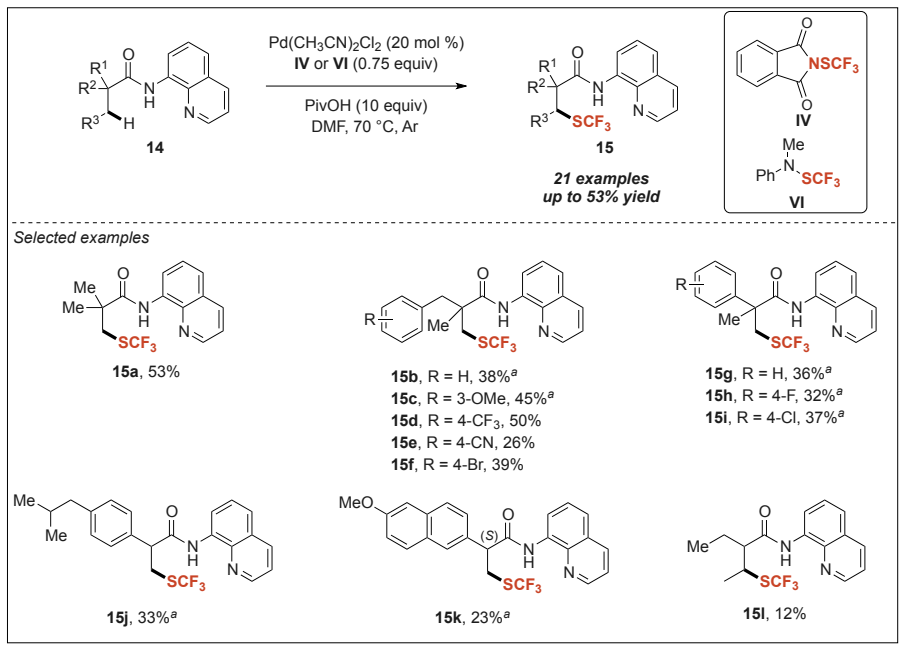

Scheme 7. $\operatorname{Pd}(॥)$-catalyzed trifluoromethythiolation of aliphatic amides by C-H bond activation. a: VI was used instead of IV.

Pleasingly, when other electrophilic sources were used under similar reaction conditions, an access to other highly appealing compounds was possible. Hence, in the presence of the $N$-chlorosuccinimide (VII), a Pd-catalyzed chlorination of unactivated $\mathrm{C}\left(\mathrm{sp}^{3}\right)-\mathrm{H}$ bond was developed at room temperature, offering an access to interesting building blocks for chemical industry (Scheme 8). [46] Starting from aliphatic amides 16, a panel of chlorinated derivatives $\mathbf{1 7}$ was synthetized and by slightly tuning the reaction conditions, the di-chlorination reaction was also possible leading selectively to the corresponding products $\mathbf{1 8}$.

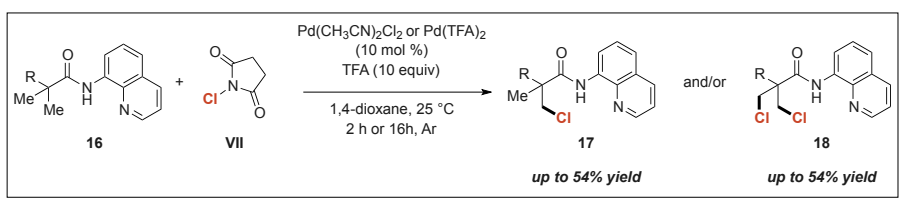

Scheme 8. $\mathrm{Pd}(\mathrm{II})$-catalyzed chlorination of unactivated $\mathrm{C}\left(\mathrm{sp}^{3}\right)-\mathrm{H}$ bond using the $\mathrm{N}$-chlorosuccinimide as the coupling partner.

Despite the advances made in the blossoming $\mathrm{C}\left(\mathrm{sp}^{3}\right)-\mathrm{H}$ bond activation research field, the functionalization of $\mathrm{C}\left(\mathrm{sp}^{3}\right)$ centers by $\mathrm{C}-\mathrm{H}$ bond activation at a remote position from a functional group remains still in its infancy. Among the different strategies developed to tackle this synthetic issue, solutions based on radical processes involving a 1,5-Hydrogen-Atom Transfer (HAT) emerged. ${ }^{477]}$ From the pioneered works from Studer ${ }^{[48]}$ and Cook, ${ }^{[49]}$ our group described, for the first time in 2020, a photoinduced remote $\delta$-trifluoromethylthiolation of primary, even secondary and tertiary alcohols $\mathbf{1 9}$ using the $S$-(trifluoromethyl)4-methylbenzenesulfonothioate (VIII) as the $\mathrm{SCF}_{3}$ source in the presence of PIDA (Scheme 9). [50]

\begin{tabular}{|c|c|c|c|}
\hline \multirow[b]{3}{*}{19} & \multirow[b]{3}{*}{ VIII } & 1) PIDA (2.3 equiv.) & $R^{2} R^{1}$ \\
\hline & & $\begin{array}{l}\mathrm{CH}_{2} \mathrm{Cl}_{2}, 20^{\circ} \mathrm{C}, 16 \mathrm{~h}, \mathrm{Ar} \\
\text { Blue LED }(450-455 \mathrm{~nm})\end{array}$ & ${ }^{\mathrm{R}^{4}} \mathrm{SCF}_{3}$ \\
\hline & & 2) $\mathrm{MeCOCl}, 20^{\circ} \mathrm{C}, 10 \mathrm{~min}, \mathrm{Ar}$ & $\begin{array}{c}20 \\
16 \text { examples } \\
\text { up to } 51 \% \text { yield }\end{array}$ \\
\hline
\end{tabular}

Scheme 9. $\delta$-Trifluoromethylthiolation of alcohols under visible light.

\section{Conclusion}

In this account, an overview of our recent contributions towards innovative methodologies for the synthesis of fluorinated molecules was given. Indeed, the combination of organofluorine chemistry and transition metal-catalyzed $\mathrm{C}-\mathrm{H}$ bond activation proved to be a powerful tool to access original fluorinated scaffolds. Novel methodologies were developed, offering unprecedented transformations for the introduction of a $\mathrm{CF}_{3}$ group, the emergent $\mathrm{SCF}_{3}$ one and even the $\alpha$-(trifluoromethyl)vinyl moiety by $\mathrm{C}-\mathrm{H}$ bond activation. These efficient strategies opened new perspectives for the synthesis of high-value added fluorinated scaffolds and we do believe that they will be inspiring to the scientific community.

\section{Acknowledgements}

This work was partially supported by Normandie Université (NU), the Région Normandie, the Centre National de la Recherche Scientifique (CNRS), Université de Rouen Normandie (URN), INSA Rouen Normandie, Labex SynOrg (ANR-11-LABX-0029) and Innovation Chimie Carnot (I2C). S.M., M.I.L. and T.B. thank the European Research Council (ERC) under the European Union's Horizon 2020 research and innovation program (grant agreement no. 758710).

Received: September 4, 2020

[1] For selected reviews, see: a) T. Liang, C. N. Neumann, T. Ritter, Angew. Chem. Int. Ed. 2013, 52, 8214; b) G. Landelle, A. Panossian, S. Pazenok, J.P. Vors, F. R. Leroux, Beilstein J. Org. Chem. 2013, 9, 2476; c) G. Landelle, A. Panossian, F. R. Leroux, Curr. Top. Med. Chem. 2014, 14, 941; d) H. Egami, M. Sodeoka, Angew. Chem. Int. Ed. 2014, 53, 8294; e) E. Merino, C. Nevado, Chem. Soc. Rev. 2014, 43, 6598; f) M. Belhomme, T. Besset, T. Poisson, X. Pannecoucke, Chem. Eur. J. 2015, 21, 12836; g) P. A Champagne, J. Desroches, J.-D. Hamel, M. Vandamme, J.-F. Paquin, Chem. Rev. 2015, 115, 9073; h) T. Besset, T. Poisson, X. Pannecoucke, J. Fluorine Chem. 2015, 178, 225; i) C. Ni, J. Hu, Chem. Soc. Rev. 2016, 45, 5441; j) H.-Y. Xiong, X. Pannecoucke, T. Besset, Chem. Eur. J. 2016, 22, 16734; k) T. Besset, P. Jubault, X. Pannecoucke, T. Poisson, Org. Chem. Front. 2016, 3 , $1004 ; 1)$ D. E. Yerien, S. Barata-Vallejo, A. Postigo, Chem. Eur. J. 2017, 23 , 14676; m) H.-X. Song, Q.-Y. Han, C.-L. Zhao, C.-P. Zhang, Green Chem. 2018, 20, 1662; n) A. Lemos, C. Lemaire, A. Luxen, Adv. Synth. Catal. 2019, 361, 1500; o) E. Carbonnel, T. Poisson, P. Jubault, X. Pannecoucke, T. Besset. Front. Chem. 2019, 7, 111; p) X. Pannecoucke, T. Besset, Org. Biomol. Chem. 2019, 17, 1683; q) S. Caron, Org. Process Res. Dev. 2020 , 24, 470 .

[2] For selected examples, see: a) J. Wang, M. Sánchez-Roselló, J. L. Aceña, C. Del Pozo, A. E. Sorochinsky, S. Fustero, V. A. Soloshonok, H. Liu, Chem. Rev. 2014, 114, 2432; b) E. P. Gillis, K. J. Eastman, M. D. Hill, D. J. Donnelly, N. A. Meanwell, J. Med. Chem. 2015, 58, 8315; c) Y. Zhou, J. Wang, Z. Gu, S. Wang, W. Zhu, J. L. Aceña, V. A. Soloshonok, K. Izawa, H. Liu, Chem. Rev. 2016, 116, 422; d) H. Mei, J. Han, S. Fustero, M. Medio-Simon, D. M. Sedgwick, C. Santi, R. Ruzziconi, V. A. Soloshonok, Chem. Eur. J. 2019 25, 11797; e) M. Inoue, Y. Sumii, N. Shibata. ACS Omega 2020, 5, 10633 f) B. M. Johnson, Y.-Z. Shu, X. Zhuo, N.A. Meanwell, J. Med. Chem. 2020 63, 6315; g) S. Purser, S. Swallow, V. Gouverneur, Chem. Soc. Rev. 2008 37, 320; h) S. Swallow, 'Fluorine in Medicinal Chemistry' in 'Progress in Medicinal Chemistry', Vol 54, Ed. G. Lawton, D. R. Witty, Elsevier, 2015; i) P. Jeschke, ChemBioChem 2004, 5, 570; j) G. Theodoridis, 'FluorineContaining Agrochemicals: An Overview of Recent Developments' in 'Fluorine and the Environment', Vol. 2, Ed. A. Tressaud, Elsevier, 2006; k) D. O'Hagan, J. Fluorine Chem. 2014, 167, 16; 1) M. Braun, J. Eicher, 'The Fluorine Atom in Health Care and Agrochemical Applications: A Contribution to Life Science' in 'Modern Synthesis Processes and Reactivity of Fluorinated Compounds', Eds H. Groult, F. R. Leroux, A. Tressaud, Elsevier, 2017; m) M. El Qacemi, S. Rendine, P. Maienfisch, 'Recent applications of fluorine in crop protection-new discoveries originating from the unique heptafluoroisopropyl group' in 'Progress in Fluorine Science, Fluorine in Life Sciences: Pharmaceuticals, Medicinal Diagnostics, and Agrochemicals'. Eds G. Haufe, F. R. Leroux, Academic Press, 2019; n) R. Berger, G. Resnati, P. Metrangolo, E. Weber, J. Hulliger, Chem. Soc. Rev. 2011, 40, 3496; o) J. H. Yun, S. Park, J. H. Heo, H.-S. Lee, S. Yoon, J. Kang, S. H. Im, H. Kim, W. Lee, B. Kim, M. J. Ko, D. S. Chung, H. J. Son, Chem. Sci. 2016, 7, 6649; p) G.-H. Kim, H. Jang, Y. J. Yoon, J. Jeong, S. Y. Park, B. Walker, I.-Y. Jeon, Y. Jo, H. Yoon, M. Kim, J.-B. Baek, D. S. Kim, J. Y. Kim, Nano Lett. 2017, 17, 6385.

[3] D. O'Hagan, Chem. Soc. Rev. 2008, 37, 308.

[4] For selected reviews, see: a) T. M. Lyons, M. S. Sanford, Chem. Rev. 2010 110, 1147; b) R. Jazzar, J. Hitce, A. Renaudat, J. Sofack-Kreutzer, O. 
Baudoin, Chem. Eur. J. 2010, 16, 2654; c) K. Engle, T.-S. Mei, M. Wasa, J.-Q. Yu, Acc. Chem. Res. 2012, 45, 788; d) N. Kuhl, M. N. Hopkinson, J. Wencel-Delord, F. Glorius, Angew. Chem. Int. Ed. 2012, 51, 10236; e) Z.-K., Chen, B. Wang, J.-T. Zhang, W.-L, Yu, Z.-X. Liu, Y.-H. Zhang, Org. Chem. Front. 2015, 2, 1107; f) J. F. Hartwig, J. Am. Chem. Soc. 2016, 138, 2; g) G. Pototschnig, N. Maulide, M. Schnürch, Chem. Eur. J. 2017, 23, 9206; h) C. Sambiagio, D. Schönbauer, R. Blieck, T. Dao-Huy, G. Pototschnig, P. Schaaf, T. Wiesinger, M. F. Zai, J. Wencel-Delord, T. Besset, B. U. W. Maes, M. A. Schnürch, Chem. Soc. Rev. 2018, 47, 6603; i) C. Ma, P. Fang, T.-S. Mei, ACS Catal. 2018, 8, 7179; j) Y. Xu, G. Dong, Chem. Sci. 2018, 9, 1424; k) P. Gandeepan, T. Muller, D. Zell, G. Cera, S. Warratz, L. Ackermann, Chem. Rev. 2019, 119, 2192; 1) For an issue on $\mathrm{C}-\mathrm{H}$ bond activation, see: R. H. Crabtree, A. Lei, Chem. Rev. 2017, 117, 8481.

[5] For selected reviews, see: a) J. Yamaguchi, A. D. Yamaguchi, K. Itami, Angew. Chem. Int. Ed. 2012, 51, 8960; b) T. Cernak, K. D. Dykstra, S. Tyagarajan, P. Vachal, S. W. Krska, Chem. Soc. Rev. 2016, 45, 546; c) R. R. Karimov, J. F. Hartwig, Angew. Chem. Int. Ed. 2018, 57, 4234; d) O. Baudoin, Angew. Chem. Int. Ed. 2020, 59, 17798 and references therein.

[6] For selected reviews, see: a) T. Besset, T. Poisson, X. Pannecoucke, Chem. Eur. J. 2014, 20, 16830; b) C. Chatalova-Sazepin, R. Hemelaere, J.-F. Paquin, G. M. Sammis, Synthesis 2015, 47, 2554; c) S. Fustero, D. M. Sedgwick, R. Román, P. Barrio, Chem. Commun. 2018, 54, 9706; d) R. Szpera, D. F. J. Moseley, L. B. Smith, A. J. Sterling, V. Gouverneur, Angew. Chem. Int. Ed. 2019, 58, 14824; e) X. Li, X. Shi, X. Li, D. Shi, Beilstein J. Org. Chem. 2019, 15, 2213; f) Q. Cheng, T. Ritter, Trends Chem. 2019, 1, 461.

[7] a) O. A. Tomashenko, V. V. Grushin, Chem. Rev. 2011, 111, 4475; b) T. Furuya, A. S. Kamlet, T. Ritter, Nature 2011, 473, 470; c) T. Besset, C. Schneider, D. Cahard, Angew. Chem. Int. Ed. 2012, 51, 5048; d) H. Liu, Z. Gu, X. Jiang, Adv. Synth. Catal. 2013, 355, 617; e) X.-F. Wu, H. Neumann, M. Beller, Chem. Asian J. 2012, 7, 1744; f) K. Sato, A. Tarui, M. Omote, A. Ando, I. Kumadaki, Synthesis 2010, 11, 1865; g) M. A. McClinton, D. A. McClinton, Tetrahedron 1992, 48, 6555; h) A. Hafner, T. S. Fischer, S. Bräse, Eur. J. Org. Chem. 2013, 7996.

[8] For selected reviews, see: a) T. Besset, T. Poisson, X. Pannecoucke, Eur. $J$ Org. Chem. 2015, 2765; b) Y. Zeng, C. Ni, J. Hu, Chem. Eur. J. 2016, 22, 3210 ; c) C. Ni, M. Hu, J. Hu, Chem. Rev. 2015, 115, 765; d) J. Charpentier, N. Früh, A. Togni, Chem. Rev. 2015, 115, 650; e) P. Chen, G. Liu, Synthesis 2013, 45, 2919; f) M. Shimizu, T. Hiyama, Angew. Chem. Int. Ed. 2005, 44, 214; g) S. Z. Zard, Org. Biomol. Chem. 2016, 14, 6891; h) S. Barata-Vallejo, A. Postigo, Chem. Eur. J. 2020, 26, 11065; i) C. Alonso, E. M. de Marigorta, G. Rubiales, F. Palacios, Chem. Rev. 2015, 115, 1847; j) S. Barata-Vallejo, B. Lantaño, A. Postigo, Chem. Eur. J. 2014, 20, 16806.

[9] For selected papers, see: a) A. T. Parsons, T. D. Senecal, S. L. Buchwald, Angew. Chem. Int. Ed. 2012, 51, 2947; b) E. J. Cho, S. L. Buchwald, Org. Lett. 2011, 13, 6552; c) G. K. S. Prakash, H. S. Krishnan, P. V. Jog, A. P. Iyer, G. A. Olah, Org. Lett. 2012, 14, 1146; d) M. Omote, M. Tanaka, A. Ikeda, S. Nomura, A. Tarui, K. Sato, A. Ando, Org. Lett. 2012, 14, 2286; e) L. Chu, F.-L. Qing, Org. Lett. 2010, 12, 5060; f) P. G. Janson, I. Ghoneim, N. O. Ilchenko, K. J. Szabó, Org. Lett. 2012, 14, 2882; g) X. Zhang, F.-L. Qing, Y. Yang, J. Yu, X.-K. Fu, Tetrahedron Lett. 2000, 41, 2953; h) M. Shimizu, T. Fujimoto, H. Minezaki, T. Hata, T. Hiyama, J. Am. Chem. Soc. 2001, 123, 6947; i) T. Kobayashi, T. Eda, O. Tamura, H. Ishibashi, J. Org. Chem. 2002, 67, 3156; j) L. Debien, B. Quiclet-Sire, S. Z. Zard, Org. Lett. 2012, 14, 5118; k) R. Tomita, Y. Yasu, T. Koike, M. Akita, Beilstein J. Org. Chem. 2014, 10, 1099; 1) K. Aikawa, N. Shimizu, K. Honda, Y. Hioki, K. Mikami. Chem. Sci. 2014, 5, 410; m) Q.-Y. Lin, X.-H. Xu, F.-L. Qing, J. Org. Chem. 2014, 79, 10434; n) H. Lin, X. Dong, Y. Li, Q. Shen, L. Lu, Eur. J. Org. Chem. 2012, 4675; o) S.-Z. Sun, H. Xu, H.-X. Dai, Chin. Chem. Lett. 2019, 30, 969; p) J. Mestre, A. Lishchynskyi, S. Castillón, O. Boutureira, J. Org. Chem. 2018, 83, 8150; q) S. Wu, X. Wu, D. Wang, C. Zhu, Angew. Chem. Int. Ed. 2019, 58, 1499; r) M. Brochetta, T. Borsari, A. Gandini, S. Porey, A. Deb, E. Casali, A. Chakraborty, G. Zanoni, D. Maiti, Chem. Eur. J. 2019, 25, 750; s) L.-H. Wu, K. Zhao, Z.-L. Shen, T.-P. Loh, Org. Chem. Front. 2017, 4, 1872; t) N. J. W. Straathof, S. E. Cramer, V. Hessel, T. Noël, Angew. Chem. Int. Ed. 2016, 55, 15549; u) F.-G. Zhang, N. Lv, Y. Zheng, J.-A. Ma, Chin. J. Chem. 2018, 36, 723; v) S.-L. Zhang, H.-X. Wan, W.-F. Bie, Org. Lett. 2017, 19, 6372; w) J.-J. Ma, W.-B. Yi, G.-P. Lu, C. Cai, Adv. Synth. Catal. 2015, 357, 3447; x) A. Hafner, S. Bräse, Adv. Synth. Catal. 2011, 353, 3044; y) R. Hemelaere, J. Desroches, J.-F. Paquin, Org. Lett. 2015, 17, 1770 .

[10] a) P. Wipf, T. C. Henninger, S. J. Geib, J. Org. Chem. 1998, 63, 6088; b) J. Xiao, B. Weisblum, P. Wipf, J. Am. Chem. Soc. 2005, 127, 5742; c) P. Wipf, J. Xiao, S. J. Geib, Adv. Synth. Catal. 2005, 347, 1605; d) K. Kobayashi, T. Narumi, S. Oishi, H. Ohno, N. Fujii, J. Org. Chem. 2009, 74, 4626.

[11] For selected examples, see: a) K. Monostory, K. Jemnitz, L. Vereczkey, G. Czira, Drug Metabolism and Disposition 1997, 25, 1370; b) H.-J. Lu, R. B. Silverman, J. Med. Chem. 2006, 49, 7404; c) Y. Wataya, A. Matsuda, D. V. Santi, D. E. Bergstrom, J. L. Ruth, J. Med. Chem. 1979, 22, 339; d) D. E. Bergstrom, J. L. Ruth, P. A. Reddy, E. D. Clercq, J. Med. Chem. 1984, 27, 279; e) P. D. Bentley, R. Cheetham, R. K. Huff, R. Pascoe, J. D. Sayle, Pestic. Sci. 1980, 11, 156; f) H. Mack, M. Hanack, Angew. Chem. Int. Ed. Engl. 1986, 25, 184; g) H. Mack, M. Hanack, Liebigs Ann.
Chem. 1989, 833; h) U. M. Nägele, M. Hanack, Liebigs Ann. Chem. 1989, 847; i) I. Guerrero, A. Correa, Asian J. Org. Chem. 2020, DOI: 10.1002/ ajoc.202000170; j) A. Rivkin, T.-C. Chou, S. J. Danishefsky, Angew. Chem. Int. Ed. 2005, 44, 2838; k) M. Shimizu, Y. Takeda, M. Higashi, T. Hiyama, Angew. Chem. Int. Ed. 2009, 48, 3653; 1) M. Shimizu, Y. Takeda, M. Higashi, T. Hiyama, Chem. Asian J. 2011, 6, 2536; m) Z. Shi, J. Davies, S.-H. Jang, W. Kaminsky, A. K.-Y. Jen, Chem. Commun. 2012, 48, 7880; n) V. Erdélyi-Tóth, F. Gyergyay, I. Számel, E. Pap, J. Kralovánszky, E. Bojti, M. Csörgó, S. Drabant, I. Klebovich, Anti-Cancer Drugs 1997, 8, 603; o) X. Liu, M. Shimizu, T. Hiyama, Angew. Chem. Int. Ed. 2004, 43, 879; p) H. Liu, M. Zhao, C. Zhang, Y. Ma, W. Liu, Toxicology 2008, 253, 89; q) A. A. Carmine, R. N. Brogden, R. C. Heel, T. M. Speight, G. S. Avery, Drugs 1982, 23, 329 .

[12] For selected examples, see: a) N. Iqbal, S. Choi, E. Kim, E. J. Cho, J. Org. Chem. 2012, 77, 11383; b) H. Egami, R. Shimizu, M. Sodeoka, Tetrahedron Lett. 2012, 53, 5503; c) C. Feng, T.-P. Loh, Chem. Sci. 2012, 3, 3458; d) X.-P. Wang, J.-H. Lin, C.-P. Zhang, J.-C. Xiao, X. Zheng, Beilstein J. Org. Chem. 2013, 9, 2635; e) R. Rey-Rodriguez, P. Retailleau, P. Bonnet, I. Gillaizeau, Chem. Eur. J. 2015, 21, 3572 .

[13] a) H.-R. Zhang, C. Xiao, S.-L. Zhang, X. Zhang, Adv. Synth. Catal. 2019, 361, 5305; b) C. Xu, W. Huang, R. Zhang, C. Gao, Y. Li, M. Wang, J. Org. Chem. 2019, 84, 14209.

[14] C. Feng, T.-P. Loh, Angew. Chem. Int. Ed. 2013, 52,12414.

[15] T. Besset, D. Cahard, X. Pannecouke, J. Org. Chem. 2014, 79, 413.

[16] J. Jiang, Q. Zhao, '2-Bromo-3,3,3-trifluoropropene', in 'Encyclopedia of Reagents for Organic Synthesis', for selected examples regarding the use of BTP in organic synthesis, 2017.

[17] a) X. Jin, X. Zhou, G. Liao, J. Wang, Procedia Eng. 2013, 62, 884; b) V. I. Babushok, G. T. Linteris, D. R. Burgess Jr., P. T. Baker, Combust. Flame 2015, 162, 1104; c) X. Ni, W. K. Chow, Fire Mater. 2013, 38, 673; d) D. R. Burgess Jr., V. I. Babushok, G. T. Linteris, J. A. Manion, Int. J. Chem. Kinet. 2015, 47, 533 .

[18] a) A.-J. Wang, Y.G. Lou, L. Zhao, F.-H. Gou, L. Wang, Y. Yu, J. Gu, C.-Y. He, Synth. Commun. 2019, 49, 3329; b) C.-M. Hu, F. Hong, Y.-Y. Xu, J. Fluorine Chem. 1993, 64, 1; c) R. Pan, X. Liu, M. Deng, J. Fluorine Chem. 1999, 95, 167; d) O. Kobayashi, D. Uraguchi, T. Yamakawa, J. Fluorine Chem. 2009, 130, 591; e) O. Kobayashi, D. Uraguchi, T. Yamakawa, J. Mol. Catal. A 2009, 302, 7; f) B. Jiang, Y. Xu, J. Org. Chem. 1991, 56, 7336; g) B. Jiang, Q.-F. Wang, C.-G. Yang, M. Xu, Tetrahedron Lett. 2001, 42, 4083; h) Q. Zhao, J. Wang, T. Besset, X. Pannecoucke, J.-P. Bouillon, T. Poisson, Tetrahedron 2018, 74, 6033 .

[19] a) C. Zhu, H. Zeng, C. Liu, Y. Cai, X. Fang, H. Jiang, Org. Lett. 2020, 22, 809; b) B. A. Chalyk, K. V. Hrebeniuk, Y. V. Fil, K. S. Gavrilenko, A. B. Rozhenko, B. V. Vashchenko, O. V. Borysov, A. V. Biitseva, P. S. Lebed, I. Bakanovych, Y. S. Moroz, O. O. Grygorenko, J. Org. Chem. 2019, 84 , 15877 ; c) Z. Li, J. Dong, J. Wang, D.-Y. Yang, Z. Weng, Chem. Commun. 2019, 55, 13132; d) J. Lu, Y. Man, B. Lin, Z. Weng, RSC Adv. 2019, 9 , 30952 .

[20] Q. Zhao, T. Besset, T. Poisson, J.-P. Bouillon, X. Pannecouke, Eur. J. Org. Chem. 2016, 1,76 .

[21] a) P. D. Kiser, M. Golczak, K. Palczewski, Chem. Rev. 2014, 114, 194; b) C. A. Kuttruff, S. Geiger, M. Cakmak, P. Mayer, D. Trauner, Org. Lett. 2012, 14, 1070; c) K. D. Carter, J. S. Panek, Org. Lett. 2004, 6, 55.

[22] a) K. C. Nicolaou, S. A. Snyder, T. Montagnon, G. Vassilikogiannakis, Angew. Chem. Int. Ed. 2002, 41, 1668; b) L. Friebe, O. Nuyken, W. Obrecht, W. Adv. Polym. Sci. 2006, 204, 1; c) A. A. Fischbach, R. Anwander, Adv. Polym. Sci. 2006, 204, 155; d) J.-E. Bäckvall, R. Chinchilla, C. Nájera, M. Yus, Chem. Rev. 1998, 98, 2291; e) P. L. Coe, S. F. Sellers, J. C. Tatlow, H. C. Fielding, G. Whittaker, J. Fluorine. Chem. 1981, 18, 417.

[23] Q. Zhao, V. Tognetti, L. Joubert, T. Besset, X. Pannecoucke, J.-P. Bouillon, T. Poisson, Org. Lett. 2017, 19, 2106.

[24] a) L. Canovese, C. Santo, F. Visentin, Organometallics 2008, 27, 3577; b) P. M. Henry, J. Am. Chem. Soc. 1971, 93, 3547; c) D. Gauthier, A. T. Lindhardt, E. P. K. Olsen, J. Overgaard, T. Skrydstrup, J. Am. Chem. Soc. 2010, 132, 7998; d) J. Yu, M. J. Gaunt, J. B. Spencer, J. Org. Chem. 2002, 67, 4627

[25] a) V. G. Zaitsev, O. Daugulis, J. Am. Chem. Soc. 2005, 127, 4156; b) Z. Zhang, X. Lu, Z. Xu, Q. Zhang, X. Han, Organometallics 2001, 20, 3724; c) Z. Wang, Z. Zhang, X. Lu, Organometallics 2000, 19, 775; d) H. Shen, R. F. Jordan, Organometallics 2003, 22, 1878.

[26] Fore selected reviews, see: a) F. Toulgoat, S. Alazet, T. Billard, Eur. J. Org. Chem. 2014, 12, 2415; b) X.-H. Xu, K. Matsuzaki, N. Shibata, Chem. Rev. 2015, 115, 731; c) S. Barata-Vallejo, S. Bonesi, A. Postigo, Org. Biomol. Chem. 2016, 14, 7150; d) H. Zheng, Y. Huang, Z. Weng, Tetrahedron Lett. 2016, 57, 1397; e) C. Zhang, J. Chem. Sci. 2017, 129, 1795; f) S. Rossi, A. Puglisi, L. Raimondi, M. Benaglia, ChemCatChem. 2018, 10, 2717; g) A.-L. Barthelemy, E. Magnier, G. Dagousse, Synthesis 2018, 50, 4765; h) A. Monfareda, S. Ebrahimiasl, M. Babazadehd, S. Arshadia, E. Vessally, J. Fluorine Chem. 2019, 220, 24; i) M. Hamzehlooa, A. Hosseinianb, S. Ebrahimiasl, A. Monfarede, E. Vessally, J. Fluorine Chem. 2019, 224, 52; j) Y.-M. Lin, L.-Q. Jiang, W.-B. Yi, Asian J. Org. Chem. 2019, 8, 627; k) A. Hosseinian, Y. J. Sadeghi, S. Ebrahimiasl, A. Monfared, E. Vessally, J. Sulfur Chem. 2019, 40, 565. 
[27] a) C. Hansch, A. Leo, S. H. Unger, K. H. Kim, D. Nikaitani, E. J. Lien, J. Med. Chem. 1973, 16, 1207; b) C. Hansch, A. Leo, R. W. Taft, Chem. Rev 1991, 91, 165

[28] For selected examples, see: a) X. Shao, X. Wang, T. Yang, L. Lu, Q. Shen, Angew. Chem. Int. Ed. 2013, 52, 3457; b) R. Pluta; P. Nikolaienko. M. Rueping, M. Angew. Chem. Int. Ed. 2014, 53, 1650; c) Y. Huang, X. He, X. Lin, M. Rong, Z. Weng, Org. Lett. 2014, 16, 3284; d) Q. Lefebvre, E. Fava, P. Nikolaienko, M. Rueping, Chem. Commun. 2014, 50, 6617; e) C. Xu, B. Ma, Q. Shen, Angew. Chem. Int. Ed. 2014, 53, 9316; f) G. Danoun, B. Bayarmagnai, M. F. Gruenberg, L. J. Goossen, Chem. Sci. 2014, 5, 1312; g) B. Exner, B. Bayarmagnai, F. Jia, L. J. Goossen, Chem. Eur. J. 2015, 21, $17220 ;$ h) S. Arimori, M. Takada, N. Shibata, Dalton Trans. 2015, 44, 19456 i) Q. Glenadel, S. Alazet, A. Tlili, T. Billard, Chem. Eur. J. 2015, 21, 14694; j) J. Zheng, L. Wang, J.-H. Lin, J.-C. Xiao, S. H. Liang, Angew. Chem. Int. Ed. 2015, 54, 13236; k) G. Yin, I. Kalvet, F. Schoenebeck, Angew. Chem. Int. Ed. 2015, 54, 6809; 1) J.-B. Liu, X.-H. Xu, Z.-H. Chen, F.-L. Qing, Angew. Chem. Int. Ed. 2015, 54, 897; m) T. Yang, L. Lu, Q. Shen, Chem. Commun. 2015, 51, 5479; n) Y. Yang, L. Xu, S. Yu, X. Liu, Y. Zhang, D. A. Vicic, Chem. Eur. J. 2016, 22, 858; o) L. Jarrige, A. Carboni, G. Dagousset, G. Levitre, E. Magnier, G. Masson, Org. Lett. 2016, 18, 2906; p) X. Liu, R. An, X. Zhang, J. Luo, X. Zhao, Angew. Chem. Int. Ed. 2016, 55, 5846; q) S. Pan, Y. Huang, F.-L. Qing, Chem. Asian J. 2016, 11, 2854; r) A. B. Dürr, G. Yin, I. Kalvet, F. Napoly, F. Schoenebeck, Chem. Sci. 2016, 7, 1076; s) M. Lübcke, W. Yuan, K. J. Szabó, Org. Lett. 2017, 19, 4548; t) G. Dagousset, C. Simon, E. Anselmi, B. Tuccio, T. Billard, E. Magnier, Chem. Eur. J. 2017, 23, 4282; u) P. Saravanan, P. Anbarasan, Adv. Synth. Catal. 2018, 360, 2894; v) C.-C. Xi, Z.-M. Chen, S.-Y. Zhang, Y.-Q. Tu, Org. Lett. 2018, 20, 4227; w) F. Gelat, T. Poisson, A. T. Biju, X. Pannecoucke, T. Besset, Eur. J. Org. Chem. 2018, 3693; x) T. Qin, Q. Jiang, J. Ji, J. Luoa, X. Zhao, Org. Biomol. Chem. 2019, 17, 1763; y) Y. Ouyang, X.-H. Xu, F.-L. Qing, Angew. Chem. Int. Ed. 2019, 58, 18508

[29] For selected examples of direct C-H trifluoromethylthiolation on aromatic derivatives, see: a) L. D. Tran, I. Popov, O. Daugulis, J. Am. Chem. Soc. 2012, 134, 18237; b) C. Xu, Q. Shen, Org. Lett. 2014, 16, 2046; c) W. Yin, Z. Wang, Y. Huang, Adv. Synth. Catal. 2014, 356, 2998; d) Q. Wang, F. Xie, X. Li, J. Org. Chem. 2015, 80, 8361; e) J. Xu, P. Chen, J. Xe, G. Lui, Acta Chim. Sinica 2015, 73, 1294; f) X.-G. Liu, Q. Li, H. Wang, Adv. Synth. Catal. 2017, 359, 1942; g) M. Yoshida, K. Kawai, R. Tanaka, T. Yoshino, S. Matsunaga, Chem. Commun. 2017, 53, 5974.

[30] For selected examples of direct C-H trifluoromethylthiolation on vinylic compounds, see: a) Y.-D. Yang, A. Azuma, E. Tokunaga, M. Yamasaki, M. Shiro, N. Shibata, J. Am. Chem. Soc. 2013, 135, 8782; b) Honeker, R. A. Garza-Sánchez, M. N. Hopkinson, F. Glorius, Chem. Eur. J. 2016, 22, 4395; c) P. Zhang, M. Li, X.-S. Xue, C. Xu, Q. Zhao, Y. Liu, J. Wang, Y. Guo, L. Lu, Q. Shen, J. Org. Chem. 2016, 81, 7486; d) M.-J. Bu, G.-P. Lu, C. Cai, Org. Chem. Front. 2017, 4, 266.

[31] For selected examples of direct $\mathrm{C}-\mathrm{H}$ trifluoromethylthiolation of activated $\mathrm{C}\left(\mathrm{sp}^{3}\right)-\mathrm{H}$ benzylic bonds, see: a) C. Chen, X.-H. Xu, B. Yang, F.-L. Qing, Org. Lett. 2014, 16, 3372; b) W. Xu, W. Wang, T. Liu, J. Xie, C. Zhu, Nat. Commun. 2019, 10, 4867.

[32] For selected examples, see: a) C.-P. Zhang, D. A. Vicic, Chem. Asian J. 2012 7, 1756; b) K. Kang, C. Xu, Q. Shen, Org. Chem. Front. 2014, 1, 294.

[33] For selected examples, see: a) M. Rueping, N. Tolstoluzhsky, P. Nikolaienko, Chem. Eur. J. 2013, 19, 14043; b) P. Zhu, X. He, X. Chen, Y. You, Y. Yuan, Z Weng, Tetrahedron 2014, 70, 672; c) Y. Huang, J. Ding, C. Wu, H. Zheng, Z. Weng, J. Org. Chem. 2015, 80, 2912; d) C. Hou, X. Lin, Y. Huang, Z. Chen, Z. Weng, Synthesis 2015, 47, 969.
[34] a) For selected examples, see: A. Ferry, T. Billard, B. R. Langlois, E. Bacqué, Angew. Chem. Int. Ed. 2009, 48, 8551; b) S. Pan, H. Li, Y. Huang, X.-H. Xu, F.- L. Qing, Org. Lett. 2017, 19, 3247; c) W. Wu, W. Dai, X. Ji, S. Cao, Org. Lett. 2016, 18, 2918 .

[35] Q. Zhao, T. Poisson, X. Pannecoucke, J.-P. Bouillon, T. Besset, Org. Lett 2017, 19, 5106.

[36] Q. Zhao, M.-Y. Chen, T. Poisson, X. Pannecoucke, J. P. Bouillon, T. Besset, Eur. J. Org. Chem. 2018, 44, 6167.

[37] a) E. A. Ilardi, E. Vitaku, J. T. Njardarson, J. Med. Chem. 2014, 57, 2832; b) A. R. Murphy, J. M. J. Fréchet, Chem. Rev. 2007, 107, 1066; c) A.-M Faucher, P. W. White, C. Brochu, C. Grand-Maître, J. Rancourt, G. Fazal, J. Med. Chem. 2004, 47, 18; d) T. Castanheiro, J. Suffert, M. Donnard, M. Gulea, Chem. Soc. Rev. 2016, 45, 494; e) X. Qing, Z. Lianyang, F. Gaofeng, J. Chengan, Chin. J. Org. Chem. 2019, 39, 287; f) A. W. Erian, S. M. Sherif, Tetrahedron 1999, 55, 7957; g) K. Nikoofar, Chem. Sci. Trans. 2013, 2 , 691; h) M. Mellah, A. Voituriez, E. Schulz, Chem. Rev. 2007, 107, 5133; i) M. Gulea, M. Donnard, Curr. Green Chem. 2020, 7, 201; j) S. Rezayati, A. Ramazani, Tetrahedron 2020, 76, 131382.

[38] M.-Y. Chen, X. Pannecoucke, P. Jubault, T. Besset, J. Org. Chem. 2019, 84, 13194.

[39] S. Guo, X. Zhang, P. Tang, Angew. Chem. Int. Ed. 2015, 54, 4065.

[40] H. Wu, Z. Xiao, J. Wu, Y. Guo, J.-C. Xiao, C. Liu, Q.-Y. Chen, Angew. Chem. Int. Ed. 2015, 54, 4070.

[41] Y. Zhao, J.-H. Lin, X.-C. Hang, J.-C. Xiao. J. Org. Chem. 2018, 83, 14120.

[42] S. Mukherjee, B. Maji, A. Tlahuext-Aca, F. Glorius, J. Am. Chem. Soc. 2016, $138,16200$.

[43] H.-Y. Xiong, T. Besset, D. Cahard, X. Pannecoucke, J. Org. Chem. 2015, 80, 4204.

[44] A. Bouchard, V. Kairouz, M. Manneveau, H.-Y. Xiong, T. Besset, X. Pannecoucke, H. Lebel, J. Flow. Chem. 2019, 9, 9.

[45] R. K. Rit, M. R. Yadav, K. Ghosh, M. Shankar, A. K. Sahoo, Org. Lett. 2014 $16,5258$.

[46] H. Y. Xiong, D. Cahard, X. Pannecoucke, T. Besset, Eur. J. Org. Chem. 2016, 21,3625 .

[47] For selected reviews, see: a) S. Chiba, H. Chen, Org. Biomol. Chem. 2014, 12, 4051; b) X.-Q. Hu, J.-R. Chen, W.-J. Xiao, Angew. Chem. Int. Ed. 2017, 56, 1960; c) L. M. Stateman, K. M. Nakafuku, D. A. Nagib, Synthesis 2018 50, 1569 and references cited therein; d) X. Wu, C. Zhu, Chem. Commun. 2019, 55, 9747 and references therein; e) G. Kumar, S. Pradhan, I. Chatterjee, Chem. Asian J. 2020, 15, 651 and references cited therein; f) X. Wu, C. Zhu. Acc. Chem. Res. 2020, 53, 1620; g) N. Goswami, D. Maiti, Isr. J. Chem. 2020, 60, 303 .

[48] Y. Xia, L. Wang, A. Studer, Angew. Chem. Int. Ed. 2018, 57, 12940.

[49] A. Modak, E. N. Pinter, S. P. Cook, J. Am. Chem. Soc. 2019, 141, 18405.

[50] M. Barday, R. Blieck, L. Ruyet, T. Besset, Tetrahedron 2020, DOI: 10.1016/j. tet.2020.131153.

\section{License and Terms}

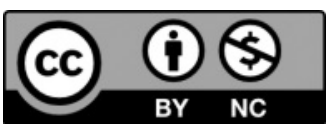

This is an Open Access article under the terms of the Creative Commons Attribution License CC BY_NC 4.0. The material may not be used for commercial purposes.

The license is subject to the CHIMIA terms and conditions: (http:// chimia.ch/component/sppagebuilder/?view=page\&id=12).

The definitive version of this article is the electronic one that can be found at https://doi.org/10.2533/chimia.2020.871 